This document was prepared in conjunction with work accomplished under Contract No. DE-AC09-96SR18500 with the U.S. Department of Energy.

This work was prepared under an agreement with and funded by the U.S. Government. Neither the U. S. Government or its employees, nor any of its contractors, subcontractors or their employees, makes any express or implied: 1 . warranty or assumes any legal liability for the accuracy, completeness, or for the use or results of such use of any information, product, or process disclosed; or 2 . representation that such use or results of such use would not infringe privately owned rights; or 3 . endorsement or recommendation of any specifically identified commercial product, process, or service. Any views and opinions of authors expressed in this work do not necessarily state or reflect those of the United States Government, or its contractors, or subcontractors. 
WSRC-STI-2008-00233

Proceedings of ASME PVP2008

2008 ASME Pressure Vessel \& Piping Division Conference

July 27-31, 2008, Chicago, IL, USA

PVP2008-61543

\title{
Foam Density Sensitivity Study for the 9977 Package
}

\author{
Jennifer L. Gorczyca \\ Savannah River National Laboratory, Aiken, SC 29808 \\ Jennifer.Gorczyca@srnl.doe.gov \\ Tsu-Te Wu \\ Savannah River National Laboratory, Aiken, SC 29808 \\ Tsu-Te.Wu@srnl.doe.gov
}

\begin{abstract}
Two layers of insulation fill the volume of the 9977 package between the drum liner and the shell. One of these layers is composed of General Plastics FR-3716 polyurethane foam (also known as Last-A-Foam $\left.{ }^{(}\right)$, poured through fill holes in the drum bottom and foamed in place. There was concern that the density of the foam insulating layer may vary due to the manufacturing process and that variations in foam density would compromise the safety basis of the package. Thus, a structural finite element analysis was performed to investigate this concern. The investigation examined the effect of replacing the material properties for the FR-3716 polyurethane foam, which has a density equal to $16 \mathrm{lb}_{\mathrm{m}} / \mathrm{ft}^{3}$, with material properties of similar foam with varying densities through finite element analysis of hypothetical accident conditions (HAC) pertaining to impact conditions. The results showed that the functional performance of the containment vessel (CV) was not compromised under the conditions investigated.
\end{abstract}

\section{INTRODUCTION}

The question was raised as to the effects of variations in foam density on the structural behavior of the polyurethane foam used for the impact-absorbing overpack. Thus, an additional analysis was completed on the structural response of the six-inch diameter $\mathrm{CV}$ in the 9977 shipping package under HAC when the overpack foam (General Plastics FR-3716 Polyurethane Foam) has density variations from 10 to $20 \mathrm{lbm} / \mathrm{ft}^{3}$ as well as when the foam had been completely removed from the packaging.

Based on prior modeling results, the case of "Side Drop Followed by Side Crush with $6 \mathrm{CV}$ ", with both $260^{\circ} \mathrm{F}$ and $300^{\circ} \mathrm{F}$ foam material properties used for the $\mathrm{CV}$, was selected for the parametric analysis of the foam density. The finite element models in this sensitivity analysis are essentially identical to that used in M-CLC-G-00358 ${ }^{[1]}$ except the foam mechanical properties corresponding to the nominal density of $16 \mathrm{lb}_{\mathrm{m}} / \mathrm{ft}^{3}$ (used in the 9977) were replaced by those based on $10,12,17$ and $20 \mathrm{lb} / \mathrm{ft}^{3}$.
To model the packaging with no foam, the elements representing the foam were removed from the finite element model. All other material properties used in the calculations were identical to those used previously.

This paper documents the following:

- Stresses within the CV.

- Strains within the cone seal region.

\section{PACKAGE}

The 9977 package is designed to meet both the requirements of Code of Federal Regulations 10 CFR $71^{[2]}$ and the Safety Series No. TS-R-1 IAEA Safety Standards ${ }^{[3]}$ to ensure that the environment and public health are not adversely impacted during transport.

The 9977 is designed to ship radioactive contents in assemblies of Radioisotope Thermoelectric Generators (RTGs) or arrangements of nested food-pack cans. These content configurations ensure product reliability, minimize contamination, simplify handling, and facilitate storage. The RTG containers are designed and tested to remain leak-tight during transport, handling and storage; however, their ability to remain leak-tight during transport in the 9977 is not credited. ${ }^{[7]}$ Figure 1 shows a cutaway view of the 9977 packaging.

\section{Finite Element Model}

Characteristics of the finite element model will be discussed in the following subsections. The model was generated using Abaqus ${ }^{\circledR} / \mathrm{CAE}$ 6.6-1 and run using ABAQUS ${ }^{\circledR} /$ Explicit version $^{-1}$ 6.6-1. ${ }^{[4]}$

\section{Geometry}

The geometry of the 9977 package is discussed in detail in S-SARP-G-00001 ${ }^{[5]}$. The geometry of the finite-element model is given in M-CLC-G-00358 ${ }^{[1]}$. The major features of the 9977 cask with the 6-in CV are shown in Figure 1. The overall model geometry was not changed for this analysis. 
Materials

The materials for each component are identical to the materials in the models documented in M-CLC-G-00358 ${ }^{[1]}$ with one exception. The material properties for the nominal foam density of $16 \mathrm{lb}_{\mathrm{m}} / \mathrm{ft}^{3}$ were replaced by those corresponding to the density of the foam under investigation for the given case study. The foam mechanical properties for various foam densities were obtained from "General Plastics Last-A-Foam FR-3700 for Crash and Fire Protection of Nuclear Material Shipping Containers ${ }^{[6] \text {, }}$

\section{Elements and Mesh}

The overall finite-element model used for the 9977 drop and crush analysis is shown in Figure 2. Figure 3 shows two different three-dimensional views of the model using the same color coding as shown in Figure 2. The arrangement of the components in the package is symmetric with respect to a plane containing the axis of the package and perpendicular to the ground. Thus, principles of symmetry were applied and only a half-model was generated.

\section{Applied Loads and Initial Conditions}

The downward gravitational force of the falling package and rigid plate is represented by the gravitational load of $386.4 \mathrm{in} / \mathrm{s}^{2}$ in the negative 2-direction of the model.

The effect of elevated and or reduced temperatures was accounted for in the foam material model. The stainless steel components of the model were assumed to be at a uniform $77^{\circ} \mathrm{F}$. Internal pressure within the $\mathrm{CV}$ was not modeled

The package model is initially located near the target floor so that the initial velocity of the package model is equal to the velocity of the package after a $30-\mathrm{ft}$ free fall in the negative 2-direction of the model. Therefore, the initial velocity of the package model can be calculated as follows.

$$
V_{0}=\sqrt{2 g h}=\sqrt{2 \times 386.4 \frac{\mathrm{in}}{\mathrm{sec}^{2}} \times 12.0 \frac{\mathrm{in}}{\mathrm{ft}} \times 30 \mathrm{ft}}=527.5 \frac{\mathrm{in}}{\mathrm{sec}}
$$

The rigid plate model which impacts the package is initially located near the package and on the side of the package opposite to the target floor. After falling 30 feet, the plate also has the initial velocity of $527.5 \mathrm{in} / \mathrm{sec}$ as calculated above. In the dynamic simulations, the falling plate impacts the package following the completion of the impact of the package with the floor after the $30-\mathrm{ft}$ free fall. The velocity of the rigid plate at the onset of its impact with the package is defined as a velocity-type boundary condition with the amplitude varying with respect to time.

Figure 4 illustrates the methodology for specifying the velocity-type boundary condition of the plate during the period traveling across the clearance between the plate and the package. The plate initially rests near the side of the package and then gradually increases its velocity to the value of $527.5 \mathrm{in} / \mathrm{sec}$ during the period from 0.020 seconds (at the end of the lateral $30-\mathrm{ft}$ drop) to 0.0201 seconds. To preclude any unintended acceleration that might be the result of numerical calculations, the rigid plate velocity is specified as a constant value of $527.5 \mathrm{in} / \mathrm{sec}$ during the period from 0.0201 seconds to 0.0210 second prior to impact. This velocity characteristic is specified as a rigid plate boundary condition.

The total duration of 0.001 seconds is an estimated value when the rigid plate will traverse preset clearance between the plate and the package culminating in impact.

\section{Boundary Conditions}

All degrees of freedom for the ground were fixed. Additionally, for nodes on the 1-2 plane of symmetry belonging to shell elements, $\mathrm{U} 3=0, \mathrm{R} 1=0$ and $\mathrm{R} 2=0$. For nodes on the $1-2$ plane of symmetry belonging to solid elements, $\mathrm{U} 3=0$.

\section{Contact Conditions}

The contact conditions between the interfaces of the package components are simulated by using the general contact option available in the ABAQUS ${ }^{\circledR} /$ Explicit code.

\section{RESULTS}

Stresses within the CV were calculated using the finite element method and will be discussed in this paper. In addition, strains within the cone seal region will also be discussed. Prior to presenting those results, the acceptance criteria will be given in the following subsection.

\section{Acceptance Criteria}

The dynamic load associated with a the $30-\mathrm{ft}$ drop or a $30-\mathrm{ft}$ crush of a 9977 package is classified as a Level D Service Load defined in the ASME Code, Section III, Appendix F 1341.2 $2^{[7]}$ and the stress limits are specified as follows:

$$
\begin{aligned}
& P_{m} \leq 0.7 S_{u} \\
& P_{L} \leq 0.9 S_{u}
\end{aligned}
$$

where $\quad P_{m}=$ General primary membrane stress intensity

$P_{L}=$ Local primary membrane stress intensity

$S_{u}=$ Ultimate strength of material

The maximum temperature under normal operating conditions is $300{ }^{\circ} \mathrm{F}$ and the minimum ultimate strength of stainless steel $304 \mathrm{~L}$ is 61.2 ksi per ASME. ${ }^{[8]}$

The results of the finite-element analysis are expressed in terms of true stresses. Thus, the allowable stress limits should also be converted to true stresses. Using the minimum required engineering elongation value of $35 \%{ }^{[9]}$, the true ultimate stress of the material at the failure strain is:

$$
S_{t u}=S_{u}(\varepsilon+1)=61.2(0.35+1)=82.62 \mathrm{ksi}
$$

for temperature $=300^{\circ} \mathrm{F}$

where,

$$
\begin{aligned}
& S_{t u}=\text { True ultimate stress of stainless steel } 304 \mathrm{~L} \text { at } 300{ }^{\circ} \mathrm{F} \\
& \varepsilon=\text { Engineering strain corresponding to ultimate strength }
\end{aligned}
$$

Consequently, the stress limits in terms of true stresses are:

$$
\begin{aligned}
& P_{m} \leq 0.7 S_{t u}=0.7 \times 82.62=57.8 \mathrm{ksi} \\
& \text { for temperature }=300^{\circ} \mathrm{F} \\
& P_{L} \leq 0.9 S_{t u}=0.9 \times 82.62=74.3 \mathrm{ksi} \\
& \text { for temperature }=300^{\circ} \mathrm{F}
\end{aligned}
$$

The allowable deformation for this analysis is chosen to be the uniform deformation limit, which is the strain level corresponding to the ultimate tensile strength (UTS). In the case of 304L stainless steel, the value is $35 \%$ (true equivalent plastic strain), as suggested by SRT-MTSD-93-3113 ${ }^{[9]}$. 


\section{Case 1: No Foam Model}

For the purposes of presenting a bounding case, the results from a model containing no foam were investigated. The maximum von Mises stress, $89.31 \mathrm{ksi}$ for the drop event and 62.60 ksi for the crush event, occurred on the outside of the shell element at the bottom of the CV during both events (Table 1 and Figure 5). The stresses across the thickness were obtained from the five evenly spaced "section points" in the shell element where the maximum von Mises stress was calculated at the same time step. These section point stresses are listed in Table 1. As this stress is located in a region of a geometric discontinuity, the failure criteria for $\mathrm{P}_{\mathrm{L}}$ is applicable. However, this high stress state is localized in a part of the small element in the surface of the $\mathrm{CV}$, and this maximum stress only occurs at a very brief moment during the impact of the 9977 package to the floor. The average von Mises stress across the local thickness of the CV, $70.51 \mathrm{ksi}$, is used to compare against the failure criterion, $\mathrm{P}_{\mathrm{L}}=74.3 \mathrm{ksi}$. As $70.51 \mathrm{ksi}$ is less than $74.3 \mathrm{ksi}$, the criterion $\mathrm{P}_{\mathrm{L}}$ is satisfied. In addition, the criterion is also satisfied for the crush event because the maximum section point stress, $62.60 \mathrm{ksi}$, is less than $\mathrm{P}_{\mathrm{L}}, 74.3 \mathrm{ksi}$.

The maximum von Mises stress for the region where $P_{M}$ is applicable (Figure 6) is shown in Table 1 and Figure 7. This value at section point $1,56.71 \mathrm{ksi}$ for the drop event and 53.51 for the crush event, is the highest value for all section points and it is less than $\mathrm{P}_{\mathrm{M}}(=57.8 \mathrm{ksi})$ for both events. Thus, the criterion for $\mathrm{P}_{\mathrm{M}}$ is also met.

Table 1 - von Mises stress results for no-foam case.

\begin{tabular}{|c|c|c|c|c|}
\hline \multirow{2}{*}{ Section Point } & \multicolumn{2}{|c|}{ Drop } & \multicolumn{2}{c|}{ Crush } \\
\cline { 2 - 5 } & $\mathbf{P}_{\mathbf{M}} \mathbf{( k s i )}$ & $\mathbf{P}_{\mathbf{L}} \mathbf{( k s i )}$ & $\mathbf{P}_{\mathbf{M}} \mathbf{( k s i )}$ & $\mathbf{P}_{\mathbf{L}} \mathbf{( k s i )}$ \\
\hline $\mathbf{1}$ (outside) & 56.71 & 89.31 & 53.51 & 62.60 \\
\hline $\mathbf{2}$ & 51.11 & 76.08 & 43.74 & 33.86 \\
\hline $\mathbf{3}$ & 46.90 & 62.05 & 8.855 & 15.13 \\
\hline $\mathbf{4}$ & 45.16 & 54.86 & 39.88 & 21.46 \\
\hline $\mathbf{5}$ (inside) & 49.98 & 70.26 & 42.73 & 33.06 \\
\hline Average & 49.97 & 70.51 & 37.74 & 33.22 \\
\hline ASME Criterion & 57.8 & 74.3 & 57.8 & 74.3 \\
\hline Element \# & 1815 & 611 & 1718 & 1885 \\
\hline
\end{tabular}

The maximum equivalent plastic strain of 0.1954 was calculated during the drop event (Table 2 and Figure 8). As the maximum von Mises stress in the drop event was higher than the maximum von Mises stress in the crush event, the equivalent plastic strain remained the same during the crush event. The maximum equivalent plastic strains correspond to the section point stresses of element 611 and are listed in Table 2. It should be noted that the maximum plastic strain is well below the uniform deformation limit (the strain corresponding to UTS), which is set to 0.35 based on the tensile properties of the material (304L stainless steel).

The deformation state in the cone seal region of the $\mathrm{CV}$ was also examined. The maximum plastic strain, $1.098 \mathrm{E}-2(\sim 1.1 \%)$, occurs in the geometrically discontinuous area in the finite element model where the shell elements meet the continuum elements in the area beneath the seal region (Figure 9). Note that in Figure 9b the gray region represents the location where the plastic strain is less than 0.005. In the actual fabrication of the CV, the smooth transition from the body of $\mathrm{CV}$ to the cone seal will prevent stress/strain concentrations from occurring. There are isolated areas in the seal where calculations show plastic deformation will take place, however, the magnitude of these plastic strains are almost undetectable (less than 0.005). Thus, the majority of the material forming the cone seal remains in an elastic state. It should be noted that the plastic strains in the cone seal region were calculated with three-dimensional continuum elements.

Table 2 - Plastic strain results - No-foam case.

\begin{tabular}{|c|c|c|}
\hline Section Point & Drop & Crush \\
\hline $\mathbf{1}$ (outside) & 0.1954 & 0.1954 \\
\hline $\mathbf{2}$ & 0.1318 & 0.1318 \\
\hline $\mathbf{3}$ & 0.07254 & 0.07254 \\
\hline $\mathbf{4}$ & 0.03615 & 0.03615 \\
\hline $\mathbf{5}$ (inside) & 0.08953 & 0.08953 \\
\hline Average & 0.1051 & 0.1051 \\
\hline Strain Limit & 0.35 & 0.35 \\
\hline Element \# & 611 & 611 \\
\hline
\end{tabular}

Case 2: Foam Density $=10 \mathrm{lb} / \mathrm{ft}^{3}$

The stresses across the thickness were obtained from the five evenly spaced "section points" in the shell element and at the time step at which the maximum von Mises stress was determined. These stresses are shown in Table 3. The maximum von Mises stress, 57.38 ksi for the drop event and $70.93 \mathrm{ksi}$ for the crush event, occurred on the outside of the shell element at the bottom of the CV during both events (Table 3). As the noted region is an area of geometric discontinuity, the maximum allowable stress intensity, $\mathrm{P}_{\mathrm{L}}$, is $74.3 \mathrm{ksi}$ (Table 3). In both cases, the maximum stress is less than $P_{L}$. Thus, the criterion is satisfied.

The maximum von Mises stress for the region where $\mathrm{P}_{M}$ is applicable is shown in Table 3. These values, $52.82 \mathrm{ksi}$ for the drop and $56.44 \mathrm{ksi}$ for the crush, are the highest values for all section points. As they are both less than $\mathrm{P}_{\mathrm{M}}=57.8 \mathrm{ksi}$, the criterion for $\mathrm{P}_{\mathrm{M}}$ is also met.

Table 3 - von Mises stress results $-10-\mathrm{lb}_{\mathrm{m}} / \mathrm{ft}^{3}$ foam case.

\begin{tabular}{|c|c|c|c|c|}
\hline \multirow{2}{*}{ Section Point } & \multicolumn{2}{|c|}{ Drop } & \multicolumn{2}{c|}{ Crush } \\
\cline { 2 - 5 } & $\mathbf{P}_{\mathbf{M}}$ (ksi) & $\mathbf{P}_{\mathbf{L}}$ (ksi) & $\mathbf{P}_{\mathbf{M}}$ (ksi) & $\mathbf{P}_{\mathbf{L}}$ (ksi) \\
\hline 1 (outside) & 52.82 & 57.38 & 56.44 & 70.93 \\
\hline $\mathbf{2}$ & 36.81 & 31.84 & 51.65 & 50.46 \\
\hline $\mathbf{3}$ & 21.34 & 32.37 & 47.00 & 45.79 \\
\hline $\mathbf{4}$ & 32.35 & 28.24 & 43.13 & 45.49 \\
\hline $\mathbf{5}$ (inside) & 43.96 & 51.09 & 44.79 & 35.20 \\
\hline Average & 37.46 & 40.18 & 48.60 & 49.57 \\
\hline $\begin{array}{c}\text { ASME } \\
\text { Criterion }\end{array}$ & 57.8 & 74.3 & 57.8 & 74.3 \\
\hline Element \# & 1815 & 611 & 1816 & 598 \\
\hline
\end{tabular}

The maximum equivalent plastic strain was calculated to be 0.1407 during the crush event (Table 4). The maximum equivalent plastic strains correspond to the section-point stresses in element 611 (drop event) and element 598 (crush event) and are shown in Table 4. It should be noted that the maximum plastic strain is well below the uniform deformation limit (the strain corresponding to UTS), which is set to 0.35 based on the tensile properties of the material $(304 \mathrm{~L}$ stainless steel).

The deformation state in the cone seal region of the $\mathrm{CV}$ was also examined. The maximum plastic strain, $2.669 \mathrm{E}-3$, occurs in the geometrically discontinuous area in the finite element model where 
the shell elements meet the continuum elements in the area beneath the seal region. In the actual construction of $\mathrm{CV}$, the smooth transition from the body of $\mathrm{CV}$ to the cone seal will result in even lower plastic strain values in this region. Thus, it is expected that the material forming the cone seal will remain in an elastic state.

Table 4 - Plastic strain results $-10-\mathrm{lb}_{\mathrm{m}} / \mathrm{ft}^{3}$ foam case.

\begin{tabular}{|c|c|c|}
\hline Section Point & Drop & Crush \\
\hline $\mathbf{1}$ (outside) & 0.05432 & 0.1407 \\
\hline $\mathbf{2}$ & 0.03146 & 0.09169 \\
\hline $\mathbf{3}$ & 0.01095 & 0.04607 \\
\hline $\mathbf{4}$ & 0.01257 & 0.02041 \\
\hline $\mathbf{5}$ (inside) & 0.03355 & 0.05928 \\
\hline Average & 0.02857 & 0.06443 \\
\hline strain limit & 0.35 & 0.35 \\
\hline Element \# & 611 & 598 \\
\hline
\end{tabular}

\section{Case 3: Foam Density $=12 \mathrm{lb} / \mathrm{ft}^{3}$}

The stresses across the thickness were obtained from the five evenly spaced "section points" in the shell element and at the time step at which the maximum von Mises stress was determined. These stresses are shown in Table 5. The maximum von Mises stress, $55.24 \mathrm{ksi}$ for the drop event and $78.99 \mathrm{ksi}$ for the crush event, occurred on the outside of the shell element at the bottom of the $\mathrm{CV}$, in a region of geometric discontinuity, during both events (Table 5). Thus, the allowable stress intensity $\mathrm{P}_{\mathrm{L}}=74.3 \mathrm{ksi}$ is applicable. The maximum value for the drop event, $55.24 \mathrm{ksi}$, is less than $74.3 \mathrm{ksi}$. Thus, the criterion is met for the drop event. As the maximum value for the crush event, 78.99 , exceeds $74.3 \mathrm{ksi}$, the average stress of the section points through the thickness of the shell element, $62.77 \mathrm{ksi}$, was used to determine that the criterion is met (Table 5).

The maximum von Mises stress for the region where $\mathrm{P}_{M}$ is applicable is shown in Table 5. These values, $53.07 \mathrm{ksi}$ for the drop event and $57.41 \mathrm{ksi}$ for the crush event, are the highest values for all section points. As they are both less than $P_{M}=57.8 \mathrm{ksi}$, the criterion for $\mathrm{P}_{\mathrm{M}}$ is also met.

Table 5 - von Mises stress results $-12-\mathrm{lb}_{\mathrm{m}} / \mathrm{ft}^{3}$ foam case.

\begin{tabular}{|c|c|c|c|c|}
\hline \multirow{2}{*}{ Section Point } & \multicolumn{2}{|c|}{ Drop } & \multicolumn{2}{c|}{ Crush } \\
\cline { 2 - 5 } & $\mathbf{P}_{\mathbf{M}}$ (ksi) & $\mathbf{P}_{\mathbf{L}}$ (ksi) & $\mathbf{P}_{\mathbf{M}}$ (ksi) & $\mathbf{P}_{\mathbf{L}}$ (ksi) \\
\hline 1 (outside) & 53.07 & 55.24 & 57.41 & 78.99 \\
\hline $\mathbf{2}$ & 32.64 & 47.26 & 51.79 & 67.65 \\
\hline $\mathbf{3}$ & 11.44 & 28.47 & 9.825 & 54.93 \\
\hline $\mathbf{4}$ & 32.68 & 44.95 & 42.58 & 50.27 \\
\hline $\mathbf{5 ~ ( i n s i d e ) ~}$ & 41.81 & 53.51 & 45.54 & 62.00 \\
\hline Average & 34.33 & 45.89 & 41.43 & 62.77 \\
\hline $\begin{array}{c}\text { ASME } \\
\text { Criterion }\end{array}$ & 57.8 & 74.3 & 57.8 & 74.3 \\
\hline Element \# & 1815 & 611 & 1816 & 598 \\
\hline
\end{tabular}

The maximum equivalent plastic strain was calculated to be 0.1471 during the crush event (Table 6). The equivalent plastic strains correspond to the section point stresses of element 611 (drop) and 598 (crush) and are shown in Table 6. It should be noted that the maximum plastic strain is well below the uniform deformation limit (the strain corresponding to UTS), which is set to 0.35 based on the tensile properties of the material (304L stainless steel).
The deformation state in the cone seal region of the $\mathrm{CV}$ was also examined. The maximum plastic strain, $2.696 \mathrm{E}-3$, occurs in the geometrically discontinuous area in the finite element model where the shell elements meet the continuum elements in the area beneath the seal region. In the actual construction of $\mathrm{CV}$, the smooth transition from the body of $\mathrm{CV}$ to the cone seal will result in a plastic strain lower than the calculated value. Thus, it is expected that the material forming the cone seal will remain in an elastic state.

Table 6 - Plastic strain results $-12-\mathrm{lb}_{\mathrm{m}} / \mathrm{ft}^{3}$ foam case.

\begin{tabular}{|c|c|c|}
\hline Section Point & Drop & Crush \\
\hline $\mathbf{1}$ (outside) & 0.06540 & 0.1471 \\
\hline $\mathbf{2}$ & 0.04013 & 0.09545 \\
\hline $\mathbf{3}$ & 0.01604 & 0.04596 \\
\hline $\mathbf{4}$ & 0.009284 & 0.02127 \\
\hline $\mathbf{5}$ (inside) & 0.03444 & 0.06198 \\
\hline Average & 0.03675 & 0.07435 \\
\hline strain limit & 0.35 & 0.35 \\
\hline Element \# & 611 & 598 \\
\hline
\end{tabular}

Case 4: Foam Density $=16 \mathrm{lb}_{\mathrm{m}} / \mathrm{ft}^{3}$ (baseline)

The stresses across the thickness were obtained from the five evenly spaced "section points" in the shell element where the maximum von Mises stress was calculated at the same time step. These section-point stresses are shown in Table 7. The maximum von Mises stress, $62.33 \mathrm{ksi}$ for the drop event and $62.48 \mathrm{ksi}$ for the crush event, occurred on the outside of the shell element at the bottom of the $\mathrm{CV}$ during both events (Table 7). As these maximum values are less than $74.3 \mathrm{ksi}$, the ASME criterion for maximum stress in a geometrically discontinuous region of the $\mathrm{CV}$, the criterion is satisfied.

The maximum von Mises stress for the region where $\mathrm{P}_{M}$ is applicable is shown in Table 7. The value at section point one, 54.75 ksi for the drop event and $57.11 \mathrm{ksi}$ for the crush event, is the highest value for all section points. As the values calculated for both the drop and crush events are less than $57.8 \mathrm{ksi}, \mathrm{P}_{\mathrm{M}}$, the criterion for $\mathrm{P}_{\mathrm{M}}$ is also met.

Table 7 - von Mises stress results $-16-1 b_{m} / \mathrm{ft}^{3}$ foam case.

\begin{tabular}{|c|c|c|c|c|}
\hline \multirow{2}{*}{ Section Point } & \multicolumn{2}{|c|}{ Drop } & \multicolumn{2}{c|}{ Crush } \\
\cline { 2 - 5 } & $\mathbf{P}_{\mathbf{M}}$ (ksi) & $\mathbf{P}_{\mathbf{L}}$ (ksi) & $\mathbf{P}_{\mathbf{M}}$ (ksi) & $\mathbf{P}_{\mathbf{L}}$ (ksi) \\
\hline 1 (outside) & 54.75 & 62.33 & 57.11 & 62.48 \\
\hline $\mathbf{2}$ & 31.36 & 33.40 & 46.32 & 45.34 \\
\hline $\mathbf{3}$ & 6.661 & 24.03 & 21.95 & 26.59 \\
\hline $\mathbf{4}$ & 25.28 & 32.81 & 33.91 & 40.80 \\
\hline 5 (inside) & 43.26 & 51.36 & 44.77 & 28.14 \\
\hline Average & 32.26 & 40.79 & 40.81 & 40.67 \\
\hline $\begin{array}{c}\text { ASME } \\
\text { Criterion }\end{array}$ & 57.8 & 74.3 & 57.8 & 74.3 \\
\hline Element \# & 1815 & 611 & 1815 & 611 \\
\hline
\end{tabular}

A maximum equivalent plastic strain of 0.07420 was calculated during the crush event (Table 8). As the maximum von Mises stress in the crush event was slightly higher than the maximum von Mises stress in the drop event, it was expected that the equivalent plastic strain would be slightly higher in the crush event as well. The equivalent plastic strains correspond to the section-point stresses of element 611 for both the drop and crush events and are shown in Table 8. It should be noted that the maximum plastic strain is well below the uniform deformation limit (the strain corresponding to 
UTS), which is set to 0.35 based on the tensile properties of the material (304L stainless steel).

The deformation state in the cone seal region of the $\mathrm{CV}$ was also examined. The maximum plastic strain is $4.456 \mathrm{E}-3(\sim 0.45 \%)$ which occurs in the geometrically discontinuous area in the finite element model where the shell elements meet the continuum elements in the area beneath the seal region. In the actual construction of $\mathrm{CV}$, the smooth transition from the body of $\mathrm{CV}$ to the cone seal will result in a lower amount of plastic strain than calculated by the finite element method. Thus, the material forming the cone seal will behave elastically.

Table 8 - Plastic strain results $-16-\mathrm{lb}_{\mathrm{m}} / \mathrm{ft}^{3}$ foam case.

\begin{tabular}{|c|c|c|}
\hline Section Point & Drop & Crush \\
\hline $\mathbf{1}$ (outside) & 0.07324 & 0.07420 \\
\hline $\mathbf{2}$ & 0.04600 & 0.04610 \\
\hline $\mathbf{3}$ & 0.02007 & 0.02810 \\
\hline $\mathbf{4}$ & 0.006977 & 0.008749 \\
\hline $\mathbf{5}$ (inside) & 0.03407 & 0.03622 \\
\hline Average & 0.03607 & 0.03867 \\
\hline strain limit & 0.35 & 0.35 \\
\hline Element \# & 611 & 611 \\
\hline
\end{tabular}

Case 5: Foam Density $=17 \mathrm{lb} / \mathrm{ft}^{3}$

The stresses across the thickness were obtained from the five evenly spaced "section points" in the shell element where the maximum von Mises stress was calculated at the same time step. These section point stresses are shown in Table 9. The maximum von Mises stress, $62.41 \mathrm{ksi}$ for the drop event and $65.63 \mathrm{ksi}$ for the crush event, occurred on the outside of the shell element at the bottom of the $\mathrm{CV}$ in a region of geometric discontinuity during both events (Table 9). As both values are less than the maximum allowable stress intensity for that region, $\mathrm{P}_{\mathrm{L}}=74.3 \mathrm{ksi}$, the criterion is met for both cases.

The maximum von Mises stress for the region where $\mathrm{P}_{M}$ is applicable is shown in Table 9. This value at section point one, $54.12 \mathrm{ksi}$ for the drop event and $56.89 \mathrm{ksi}$ for the crush event, is the highest value for all section points. As both values are less than $P_{M}$ $=57.8 \mathrm{ksi}$, the criterion for $\mathrm{P}_{\mathrm{M}}$ is also met.

Table 9 - von Mises stress results $-17-\mathrm{lb}_{\mathrm{m}} / \mathrm{ft}^{3}$ foam case.

\begin{tabular}{|c|c|c|c|c|}
\hline \multirow{2}{*}{ Section Point } & \multicolumn{2}{|c|}{ Drop } & \multicolumn{2}{c|}{ Crush } \\
\cline { 2 - 5 } & $\mathbf{P}_{\mathbf{M}} \mathbf{( k s i )}$ & $\mathbf{P}_{\mathbf{L}} \mathbf{( k s i )}$ & $\mathbf{P}_{\mathbf{M}} \mathbf{( k s i )}$ & $\mathbf{P}_{\mathbf{L}} \mathbf{( k s i )}$ \\
\hline $\mathbf{1}$ (outside) & 54.12 & 62.41 & 56.89 & 65.63 \\
\hline $\mathbf{2}$ & 29.44 & 55.04 & 49.27 & 54.69 \\
\hline $\mathbf{3}$ & 28.85 & 22.35 & 17.58 & 48.39 \\
\hline $\mathbf{4}$ & 21.87 & 45.43 & 24.36 & 21.43 \\
\hline $\mathbf{5}$ (inside) & 35.01 & 55.44 & 46.46 & 57.53 \\
\hline Average & 33.86 & 48.13 & 38.91 & 49.53 \\
\hline $\begin{array}{c}\text { ASME } \\
\text { Criterion }\end{array}$ & 57.8 & 74.3 & 57.8 & 74.3 \\
\hline Element \# & 1815 & 611 & 1814 & 1885 \\
\hline
\end{tabular}

A maximum equivalent plastic strain of 0.09116 was calculated during the crush event (Table 10). As the maximum von Mises stress in the crush event is higher than the maximum von Mises stress in the drop event, it is expected that the equivalent plastic strain would be higher for the crush event than the drop event. The equivalent plastic strains correspond to the sectionpoint stresses of elements 611 (drop event) and 1885 (crush event) and are shown in Table 10. It should be noted that the maximum plastic strain is well below the uniform deformation limit (the strain corresponding to UTS), which is set to 0.35 based on the tensile properties of the material (304L stainless steel).

The deformation state in the cone seal region of the $\mathrm{CV}$ was also examined. The maximum plastic strain is $1.043 \mathrm{E}-2 \quad(\sim 1 \%)$. However, it was noted that the high strain does not extend through to the outside of the cone seal. The high strain drops off quickly through the cross-section of the cone seal. In the actual construction of the $\mathrm{CV}$, the smooth transition from the body of $\mathrm{CV}$ to the cone seal will prevent stress/strain concentration from occurring. There are isolated areas in the seal where plastic deformation has taken place. The majority of the material forming the cone seal remains in an elastic state.

Table 10 - Plastic strain results $-17-\mathrm{lb}_{\mathrm{m}} / \mathrm{ft}^{3}$ foam case.

\begin{tabular}{|c|c|c|}
\hline Section Point & Drop & Crush \\
\hline 1 (outside) & 0.07398 & 0.09116 \\
\hline $\mathbf{2}$ & 0.04609 & 0.04896 \\
\hline $\mathbf{3}$ & 0.02007 & 0.03126 \\
\hline $\mathbf{4}$ & 0.009675 & 0.03086 \\
\hline $\mathbf{5}$ (inside) & 0.03561 & 0.06469 \\
\hline Average & 0.03709 & 0.05339 \\
\hline strain limit & 0.35 & 0.35 \\
\hline Element \# & 611 & 1885 \\
\hline
\end{tabular}

Case 6: Foam Density $=20 \mathrm{lb} / \mathrm{ft}^{3}$

The stresses across the thickness were obtained from the five evenly spaced "section points" in the shell element where the maximum von Mises stress was calculated at the same time step (Table 11). The maximum von Mises stress, $63.80 \mathrm{ksi}$ for the drop event and $67.85 \mathrm{ksi}$ for the crush event, occurred on the outside of the shell element at the bottom of the CV during both events (Table 11). As these maximum values are less than $74.3 \mathrm{ksi}$, the ASME criterion for maximum stress in a geometrically discontinuous region of the $\mathrm{CV}$, the criterion is satisfied.

The maximum von Mises stress for the region where $\mathrm{P}_{M}$ is applicable (Figure 6) is shown in Table 11. This value, at section point 1, $54.9 \mathrm{ksi}$ for the drop event and $61.64 \mathrm{ksi}$ for the crush event, is the highest value for all section points. As the value calculated during the drop event is less than $57.8 \mathrm{ksi}, \mathrm{P}_{\mathrm{M}}$, the criterion for $\mathrm{P}_{\mathrm{M}}$ is met for the drop case. When determining that the criterion was met for the crush case, the average value through the thickness of the shell element was examined. For the crush event, the average value through the thickness was calculated to be $38.32 \mathrm{ksi}$. As this value is less than $57.8 \mathrm{ksi}$, it was concluded that the criterion was met.

Table 11 - von Mises stress results $-20-\mathrm{lb}_{\mathrm{m}} / \mathrm{ft}^{3}$ foam case.

\begin{tabular}{|c|c|c|c|c|}
\hline \multirow{2}{*}{ Section Point } & \multicolumn{2}{|c|}{ Drop } & \multicolumn{2}{c|}{ Crush } \\
\cline { 2 - 5 } & $\mathbf{P}_{\mathbf{M}} \mathbf{( k s i )}$ & $\mathbf{P}_{\mathbf{L}} \mathbf{( k s i )}$ & $\mathbf{P}_{\mathbf{M}} \mathbf{( k s i )}$ & $\left.\mathbf{P}_{\mathbf{L}} \mathbf{( k s i}\right)$ \\
\hline $\mathbf{1}$ (outside) & 54.90 & 63.80 & 61.64 & 67.85 \\
\hline $\mathbf{2}$ & 51.24 & 55.74 & 51.71 & 39.61 \\
\hline $\mathbf{3}$ & 47.18 & 40.50 & 16.08 & 22.66 \\
\hline $\mathbf{4}$ & 43.24 & 45.68 & 25.75 & 26.88 \\
\hline $\mathbf{5}$ (inside) & 44.89 & 57.02 & 36.40 & 37.72 \\
\hline Average & 48.29 & 52.55 & 38.32 & 38.94 \\
\hline $\begin{array}{c}\text { ASME } \\
\text { Criterion }\end{array}$ & 57.8 & 74.3 & 57.8 & 74.3 \\
\hline Element \# & 1815 & 611 & 1717 & 1885 \\
\hline
\end{tabular}


A maximum equivalent plastic strain of 0.09783 was calculated during the crush event (Table 12). As the maximum von Mises stress in the crush event was higher than the maximum von Mises stress in the drop event, it was expected that the equivalent plastic strain would be higher in the crush event. The equivalent plastic strains correspond to the section point stresses in element 611 (drop event) and element 1885 (crush event) and are shown in Table 12. It should be noted that this plastic strain is well below the uniform deformation limit (the strain corresponding to UTS), which is set to 0.35 based on the tensile properties of the material (304L stainless steel).

The deformation state in the cone seal region of the CV has also been carefully examined. The maximum plastic strain is $4.29 \mathrm{E}-3(\sim 0.43 \%)$ which occurs in the geometrically discontinuous area in the finite element model where the shell elements meet the continuum elements in the area beneath the seal region. In the actual construction of $\mathrm{CV}$, the smooth transition from the body of $\mathrm{CV}$ to the cone seal will result in less plastic strain than was calculated by the finite element model. Thus, the material forming the cone seal will behave elastically.

Table 12 - Plastic strain results $-20-\mathrm{lb}_{\mathrm{m}} / \mathrm{ft}^{3}$ foam case.

\begin{tabular}{|c|c|c|}
\hline Section Point & Drop & Crush \\
\hline 1 (outside) & 0.07947 & 0.09783 \\
\hline $\mathbf{2}$ & 0.04880 & 0.05070 \\
\hline $\mathbf{3}$ & 0.01913 & 0.03352 \\
\hline $\mathbf{4}$ & 0.01095 & 0.03354 \\
\hline $\mathbf{5}$ (inside) & 0.05424 & 0.07073 \\
\hline Average & 0.04252 & 0.05726 \\
\hline strain limit & 0.35 & 0.35 \\
\hline Element \# & 611 & 1885 \\
\hline
\end{tabular}

\section{Summary of Results}

In all cases, it was determined that the maximum stress intensity as specified by the ASME code was satisfied. In all but one case for the drop event, the criterion for maximum allowable stress in the region of discontinuity, $\mathrm{P}_{\mathrm{L}}$, was satisfied by using the maximum stress on the outer surface of the shell element, section point 1 . This value was the maximum value of all the section points. In the case where the foam was removed from the packaging, the average stress value of the section points was calculated where the maximum section-point stress was originally calculated to show that the criterion specified by the code was met. For the crush event, in all but one case, the maximum value determined on the outer surface of the shell element at section point 1 satisfied the criterion. In the one case where the maximum section point value exceeded the criterion, the section point stresses were averaged through the thickness of the shell to show that the criterion was met.

The maximum allowable stress intensity $\mathrm{P}_{\mathrm{M}}$ was only exceeded during the crush event when $20-1 b_{m} / \mathrm{ft}^{3}$ foam was modeled. In the one case where the maximum value exceeded the criterion, the average value was computed and compared against the criterion.

When examining the stress results, it is also important to note that the maximum stress values did not always occur on the same element. However, in most cases the maximum stress values occurred in the same region. In all cases examined in this article, the $\mathrm{P}_{\mathrm{L}}$ values occurred on the surface of the $\mathrm{CV}$ closest to the ground during the crush event. As the mechanism for deformation is affected by foam density, the maximum stress is not always calculated on the same element.

The results for the maximum equivalent plastic strain in the $\mathrm{CV}$ are all below the limit of 0.35 , which was determined based on the true ultimate tensile strength.

The results of the plastic strain in the cone seal region were higher than expected because shell elements meet solid elements in this region of the model. In the actual $\mathrm{CV}$, a solid tapered region exists. As a result, the potential for stress concentrations in that region is greatly reduced in the actual $\mathrm{CV}$ when compared to the modeled CV.

\section{CONCLUSIONS}

This parametric study confirms that the stresses within the CV structure remain within the limits specified by the ASME code when the density of the foam is changed globally over the range presented in this calculation. The packaging was designed with $16-\mathrm{lb}_{\mathrm{m}} / \mathrm{ft}^{3}$ density foam. Consequently, minor variations in foam properties resulting from manufacturing perturbations or random occurrences of minor voids will result in no significant change in $\mathrm{CV}$ response to the HAC impact events. As global deviations in density were the focus of this investigation, controls should be in place to ensure that large local deviations from the nominal value for foam density do not occur.

A careful examination of the cone seal region was conducted with respect to the deformation state to ensure its functional performance. Only isolated locations in the cone seal region are slightly above the yield point of the material during the HAC events; and the degree of plastic deformation is hardly detectable. Refining the finite element mesh in the region where the shell elements meet the brick elements would remove concentrations of strain in the seal region which were less than or equal to $1.3 \%$. In such a case, it is expected that the cone seal would remain elastic even without the presence of foam in the 9977 package.

Based on the stress and deformation assessments described above, it is concluded that variations in density of the General Plastics FR-3716 Polyurethane Foam within the limits specified in the SARP, as it is installed in the 9977 overpack, should not be a concern for the performance of the package

\section{ACKNOWLEDGMENT}

This paper was prepared in connection with work done under Contract No. DE-AC09-96SR18500 with the Department of Energy. By acceptance of this paper, the publisher and/or the recipient acknowledges the U.S. Government's rights to retain a nonexclusive, royalty-free license in and to any copyright covering this paper, along with the right to reproduce and to authorize others to reproduce all or part of the copyrighted paper.

\section{REFERENCES}

1. R. R. Rothermel. Structural Evaluation of Model 9977 Package for HAC Drop and Crush (U), M-CLC-G-00358, Rev. 0, 2006.

2. Packaging and Transportation of Radioactive Material, Code of Federal Regulations, Title 10, Part 71, Washington, DC (January 2006).

3. Regulations for the Safe Transport of Radioactive Material 2005 Edition - Safety Requirements, IAEA Safety Standards Series No. TS-R-1, International Atomic Energy Agency, Vienna, Austria, 2005. 
4. ABAQUS 6.6 Manuals, Abaqus, Inc. Providence, RI, 2006.

5. Model 9977, Safety Analysis Report for Packaging (U), S-SARP-G-00001, Revision 0, Westinghouse Savannah River Company, Savannah River Site, Aiken, SC, 2007.

6. General Plastics Last-A-Foam FR-3700 for Crash and Fire Protection of Nuclear Material Shipping Containers," General Plastics Manufacturing Company, Tacoma, Washington (Reprint December 1993).

7. ASME Boiler and Pressure Vessel Code, Section III, Appendix F 1341.2, 2004.

8. ASME Boiler and Pressure Vessel Code, Section II, Part D, Properties, 2004.

9. R. L. Sindelar, SRT-MTS-93-3113, Tensile Properties of Type 304/304L Stainless Steel for Impact Deformation Analysis of Nuclear Material Containers (U), Interoffice Memorandum, Westinghouse Savannah River Company, 1993. 


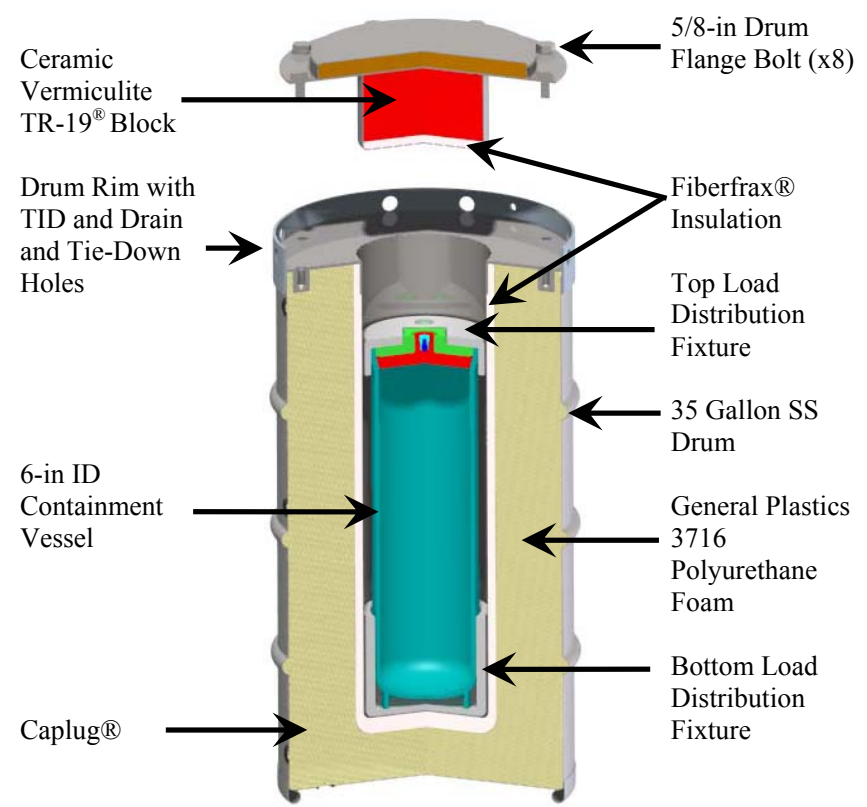

Figure 1 - Major 9977 Cask Features

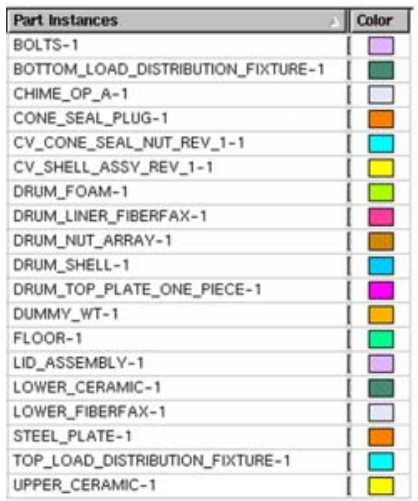

Steel Plate

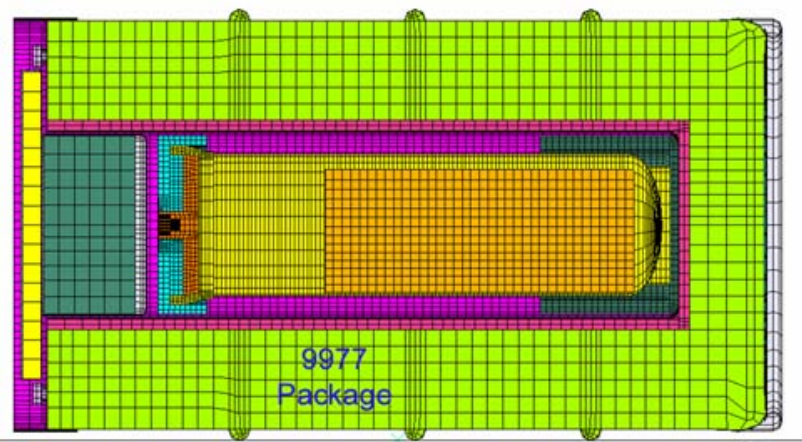

Ground

Figure 2 - Overall finite-element model of 9977 package used in drop and crush FE model
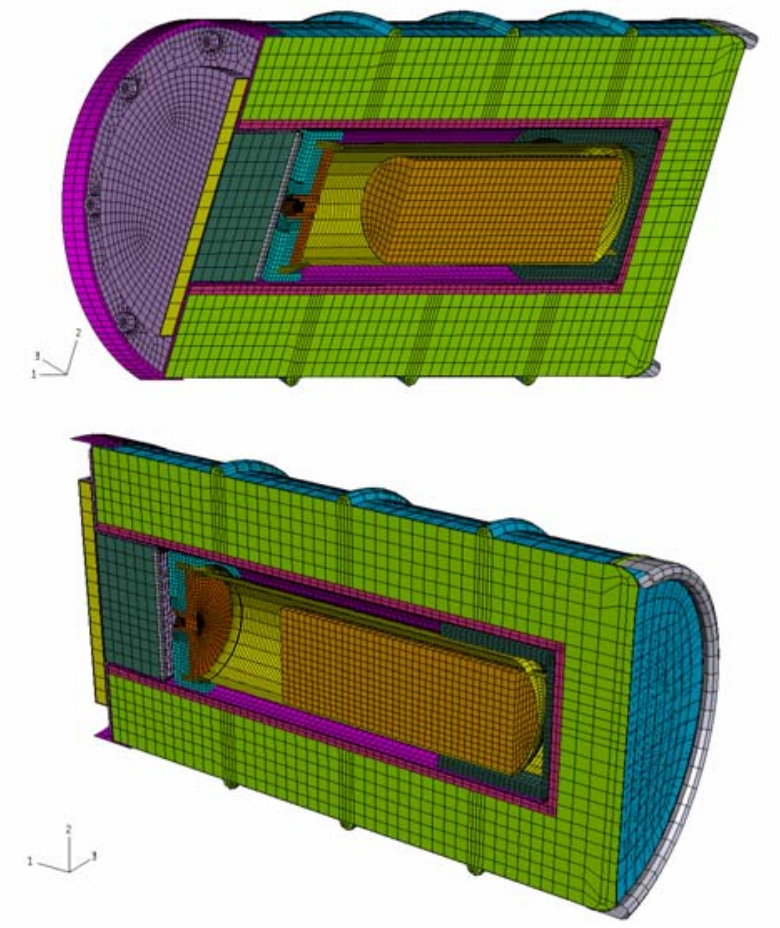

Figure 3 - Two view angles for the three-dimensional finite-element model of 9977 package

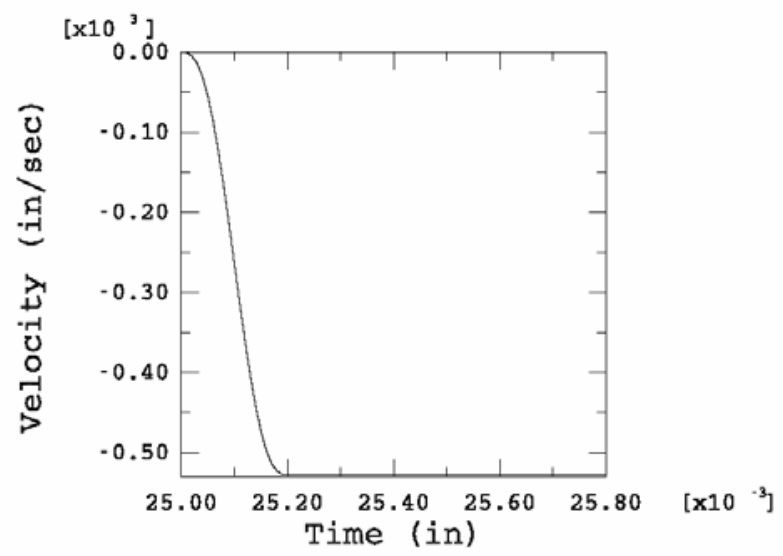

Figure 4 - Input Velocity Profile of Falling Plate 


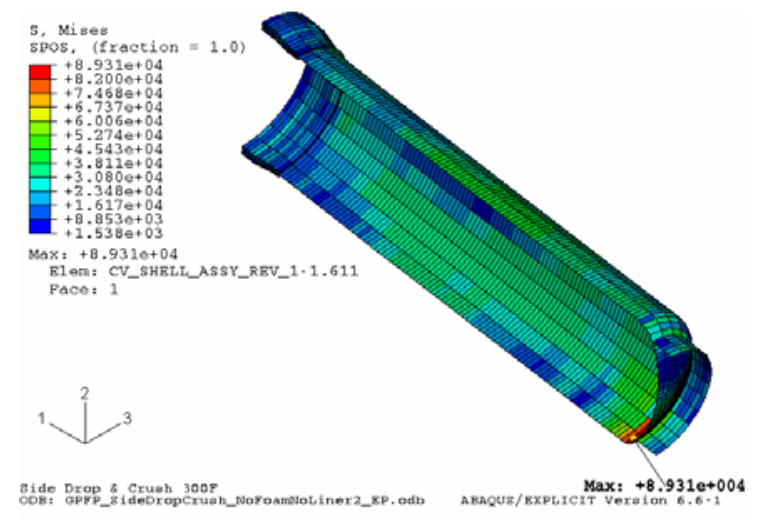

Step: Drop, Flat Bottom Drop
Increment $136808:$ step Time $=9.6000 \mathrm{E} \cdot 03$

Prinary Var: $s$, Migez
Deformed Var: $\mathrm{u}$
Deformation scale Factor:

(a)

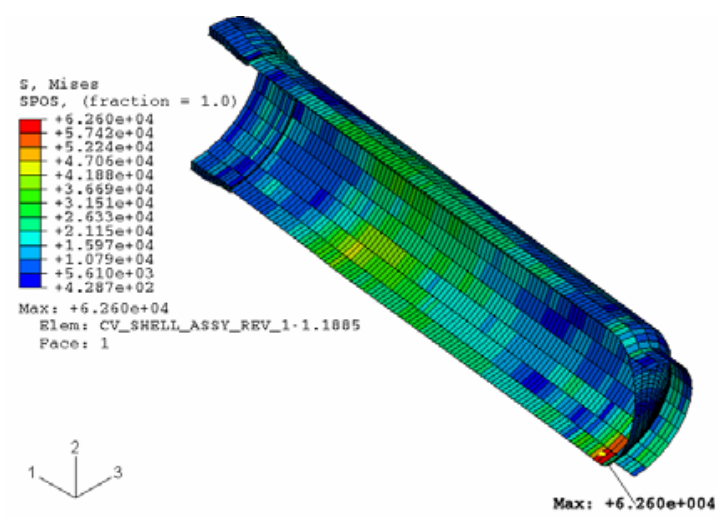

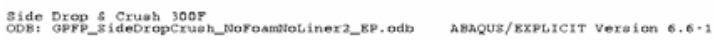

Step: Crush, Crush Package with plate
Increment $48459:$ step Time $=3.4000 \mathrm{~g} \cdot 03$

Primary Var: s, Miges
Deformed Var: u
Deformation scale Factor: $+1.0000+0$

(b)

Figure 5 - Location of Maximum von Mises Stress (No Foam) - for $\mathrm{P}_{\mathrm{L}}$ determination (a) Drop (b) Crush

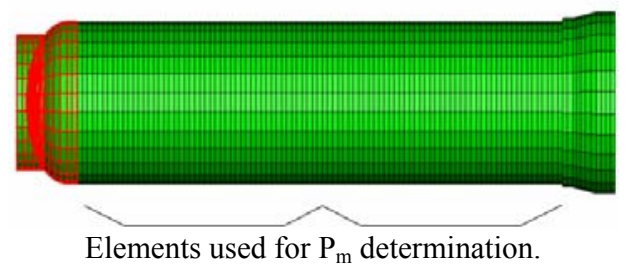

Figure 6 - Elements used for $\mathrm{P}_{\mathrm{m}}$ determination.

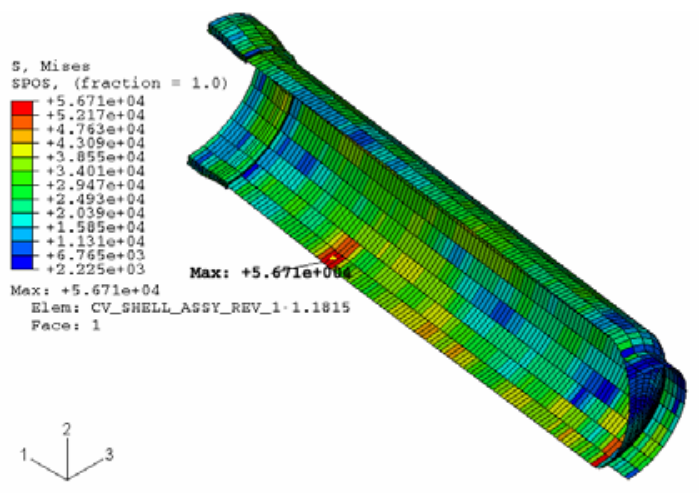

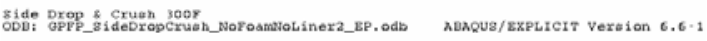

Step: Drop, Flat Botton Drop
Increment $148213:$ step Time $=1.0400 \mathrm{~g} \cdot 02$

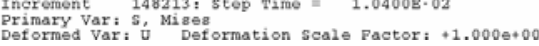

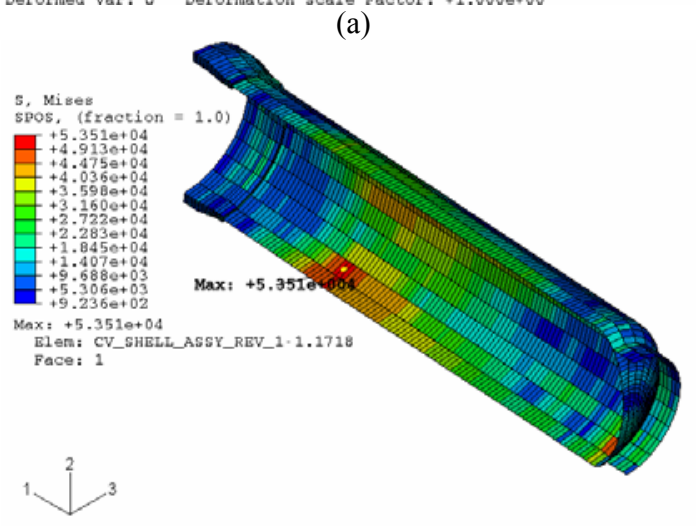

gidee Prop E. Crueh Joor

Stop: cruoh, cruch paokage with Plate
Increment $168183:$ Stop Tine $=1.1800 \mathrm{~B}-02$

Primary Var: s, Mises
Deformed Var: io
Deformation scale Factor: $+1.000 e+00$

(b)

Figure 7 - Location of maximum von Mises Stress for $\mathrm{P}_{\mathrm{M}}$ determination (No foam) (a) Drop (b) Crush 


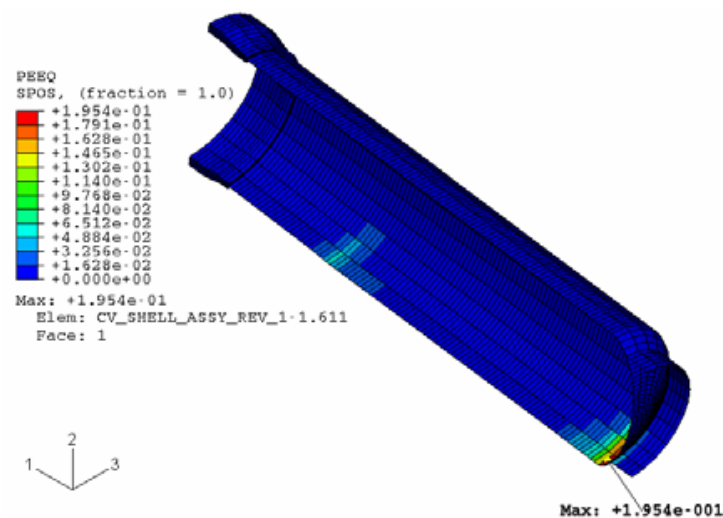

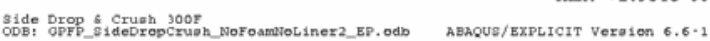

Step: Drop, F1at Bottom Drop
Increment, $205040=$ step Time $=3.0000 \mathrm{~B} \cdot 02$

Primary Var: PEEQ Deformation scale Factor: $+1.0000+00$

(a)

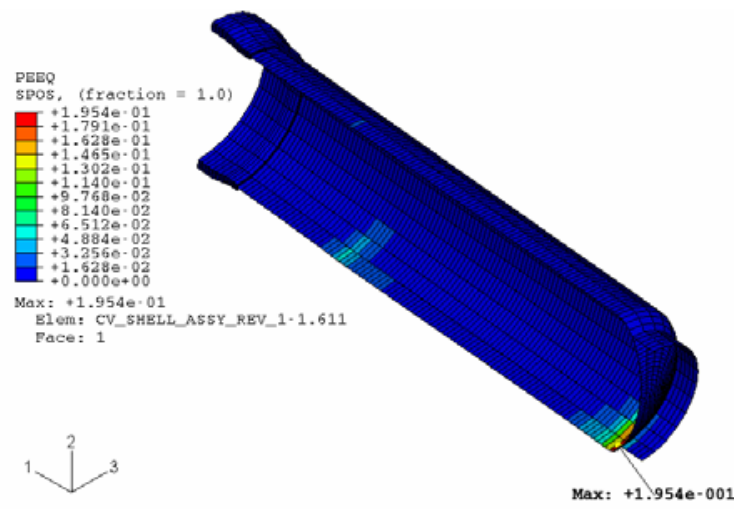

gide Drop s Crush $300 \mathrm{p}$
ODB: GPFP_

Step: Crueh, Crueh Package with plate
Increment $285054:$ Step Time $=23.0000 \mathrm{~B} \cdot 02$

Deformed Var: $\mathrm{u}$ Deformation scale Factor: +1.000 e*0

(b)

Figure 8 - Maximum plastic strain (No foam) (a) Drop (b) Crush.

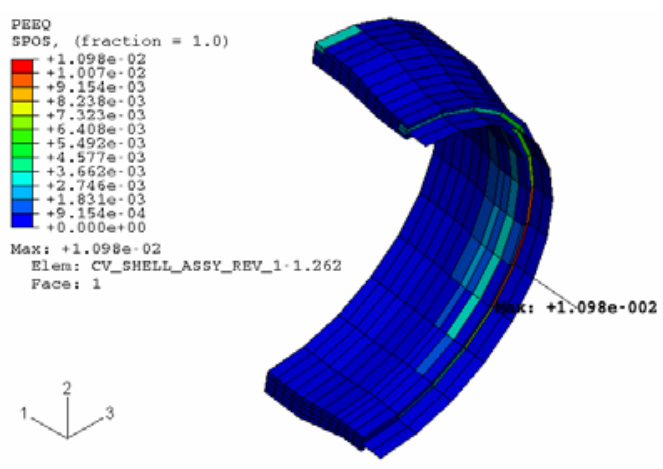

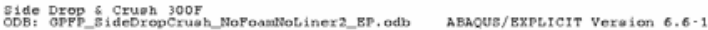
Step: Drop, Flat Botton Drop
Increment
$285040:$ step Time $=2.0000 \mathrm{E} \cdot 02$ Primary Var: PEEQ Deformation Scale Factor: $+1.000 e+00$
Deformed Var: $\mathrm{\square}$

(a)

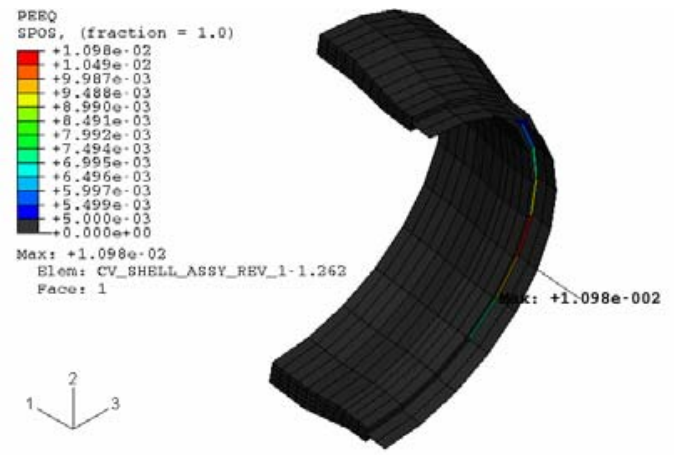

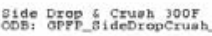
BAQUB/BXPLICIT Veration 6.6-1 Step: Drop, Flat Dottom Drop
Increnent
$285040:$ Step Time $=2.0000 \mathrm{E} \cdot 02$ Prinary Var:
Deforthod Var: 0

(b)

Figure 9 - Plastic Strains in Seal - No Foam 